\title{
Removal of highly polar micropollutants from wastewater by powdered activated carbon
}

\author{
Lubomira Kovalova • Detlef R. U. Knappe • \\ Kai Lehnberg • Christian Kazner • Juliane Hollender
}

Received: 8 November 2012 / Accepted: 12 December 2012 / Published online: 9 January 2013

(C) Springer-Verlag Berlin Heidelberg 2013

\begin{abstract}
Due to concerns about ecotoxicological effects of pharmaceuticals and other micropollutants released from wastewater treatment plants, activated carbon adsorption is one of the few processes to effectively reduce the concentrations of micropollutants in wastewater. Although aimed mainly at apolar compounds, polar compounds are also simultaneously removed to a certain extent, which has rarely been studied before. In this study, adsorption isotherm and batch kinetic data were collected with two powdered activated carbons (PACs) to assess the removal of the polar pharmaceuticals 5-fluorouracil (5-Fu) and cytarabine (CytR) from ultrapure water and wastewater treatment plant effluent. At $\mathrm{pH} 7.8$, single-solute adsorption isotherm data for the weak acid 5-Fu and the weak base CytR showed that their adsorption capacities were about 1 order of magnitude lower
\end{abstract}

Responsible editor: Vinod Kumar Gupta

Electronic supplementary material The online version of this article (doi:10.1007/s11356-012-1432-9) contains supplementary material, which is available to authorized users.

L. Kovalova $\cdot$ K. Lehnberg

Institute of Hygiene and Environmental Medicine, RWTH Aachen University, Pauwelstr. 50,

52074 Aachen, Germany

L. Kovalova $\cdot$ J. Hollender $(\bowtie)$

Eawag, Swiss Federal Institute of Aquatic Science and

Technology, Überlandstr. 133,

8600 Dübendorf, Switzerland

e-mail: juliane.hollender@eawag.ch

D. R. U. Knappe

Department of Civil, Construction, and Environmental

Engineering, North Carolina State University, Campus box 7908,

Raleigh, NC 27695, USA

C. Kazner

Department of Chemical Engineering, RWTH Aachen University,

Turmstr. 46,

52056 Aachen, Germany than those of the less polar endocrine disrupting chemicals bisphenol A (BPA) and 17- $\alpha$-ethinylestradiol (EE2). To remove $90 \%$ of the adsorbate from a single-solute solution $14,18,70$, and $87 \mathrm{mgL}^{-1}$ of HOK Super is required for EE2, BPA, CytR, and 5-Fu, respectively. Effects of solution $\mathrm{pH}$, ionic strength, temperature, and effluent organic matter (EfOM) on 5-Fu and CytR adsorption were evaluated for one PAC. Among the studied factors, the presence of EfOM had the highest effect, due to a strong competition on $5-\mathrm{Fu}$ and CytR adsorption. Adsorption isotherm and kinetic data and their modeling with a homogeneous surface diffusion model showed that removal percentage in the presence of EfOM was independent on the initial concentration of the ionizable compounds 5-Fu and CytR. These results are similar to neutral organic compounds in the presence of natural organic matter. Overall, results showed that PAC doses sufficient to remove $>90 \%$ of apolar adsorbates were able to remove no more than $50 \%$ of the polar adsorbates $5-\mathrm{Fu}$ and $\mathrm{CytR}$ and that the contact time is a critical parameter.

Keywords Adsorption - Powdered activated carbon . Wastewater treatment $\cdot$ Polar compound · Trace organic compound $\cdot$ Micropollutant $\cdot$ Pharmaceuticals $\cdot$ Cytostatic

\section{Introduction}

The development and application of advanced wastewater treatment processes for the removal of micropollutants is an intensively discussed issue (Jones et al. 2007; Joss et al. 2008). Additional treatment processes such as activated carbon adsorption or ozonation may soon become common in wastewater treatment, especially if micropollutant removal is required (Kovalova et al. 2012; Lipp et al. 2012; Serrano et al. 2011). Switzerland, for example, is the first 
country that has promulgated a new regulation that requires in the future $80 \%$ removal of micropollutants for the largest wastewater treatment plants (WWTPs; www.bafu.admin.ch). Some Swiss wastewater treatment plants are already in the process of being upgraded to achieve the targeted micropollutant removal requirements.

Adsorption is widely used for drinking water purification and has been studied for decades. Interactions between the adsorbent and adsorbate are primarily controlled by nonspecific dispersive interactions (e.g., van der Waals interactions), but electrostatic interactions between ionic adsorbates and charged adsorbent surfaces are also important (Newcombe and Dixon 2006; Yu et al. 2009). Typically, apolar or moderately polar adsorbates are evaluated in adsorption studies because activated carbon adsorption is in many instances the best available technology for the removal of such compounds. Compounds with a low octanol/water partition coefficient are considered hydrophilic or polar, and activated carbon typically exhibits lower adsorption capacities for such compounds. Nonetheless, the adsorption of polar micropollutants will take place when activated carbon is applied in wastewater treatment for the purpose of removing less polar micropollutants.

Two highly polar contaminants of emerging concern were selected for this study: cytarabine (CytR) and 5-fluorouracil (5-Fu). They are both commonly used cytostatic pharmaceuticals from the group of pyrimidine analog cytostatics (ATC L01BC). For both micropollutants, only limited removal (Kiffmeyer et al. 1998; Rey et al. 1999) and occurrence data are available (Johnson et al. 2008; Mahnik et al. 2004; Weissbrodt et al. 2009). Cytostatics are among the most toxic pharmaceuticals in common use with a potential risk to aquatic organisms (Johnson et al. 2008; Zounkova et al. 2010). Though they have been overlooked, they are of great importance (Kosjek and Heath 2011).

Pharmaceuticals are generally more polar than other micropollutants such as pesticides, biocides, material protection substances, personal care products, or hormones. To put the polarity of the target micropollutants into a context, Fig. 1 shows the comparison of octanol-water partition coefficients $\left(\log K_{\text {ow }}\right)$ for the neutral forms of 5 -Fu and CytR with those of other environmentally relevant micropollutants. In addition, trends for $\mathrm{pH}$-dependent octanolwater partition coefficients $\left(\log D_{\mathrm{ow}}\right)$ are indicated for 5$\mathrm{Fu}$ and $\mathrm{CytR}$ as well as other ionizable micropollutants (arrows in Fig. 1).

The objectives of this research were to (1) compare the adsorption of 5-Fu and $\mathrm{CytR}$ on powdered activated carbon (PAC) with adsorption of less polar micropollutants in single-solute systems; (2) evaluate effects of $\mathrm{pH}$, ionic strength, and temperature on CytR and 5-Fu adsorption; (3) describe the adsorption behavior of CytR

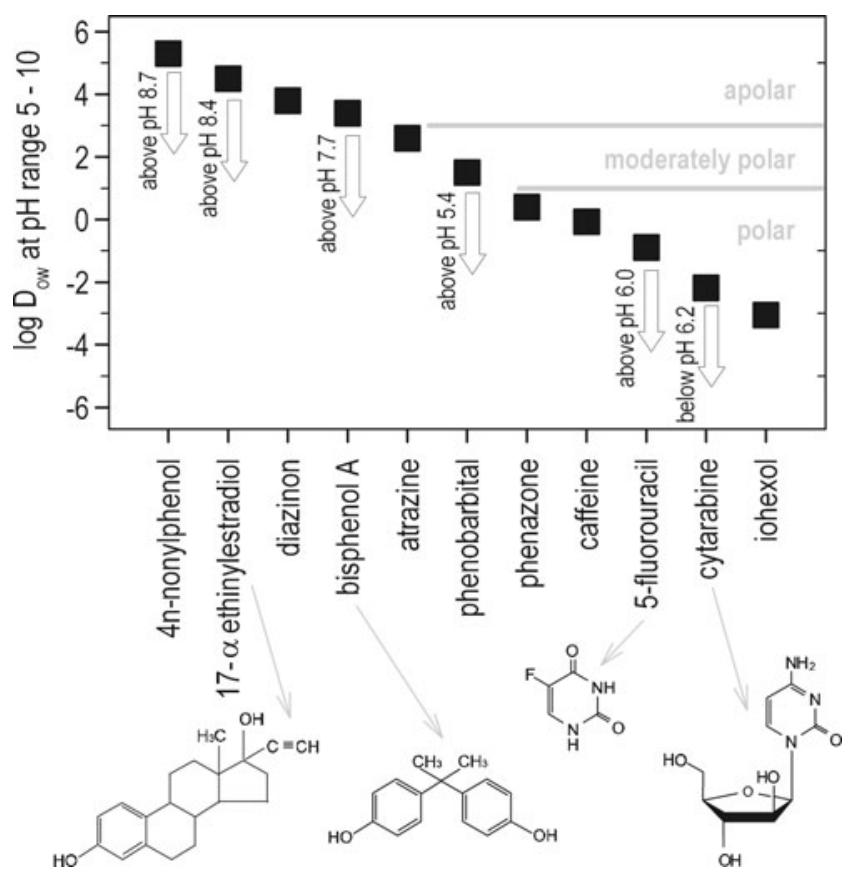

Fig. 1 Micropollutants and their octanol-water partition coefficients. Solid symbols indicate $\log K_{\mathrm{ow}}$ for the neutral form of each compound. Arrows qualitatively indicate that the $\mathrm{pH}$-dependent octanol/water partition coefficient $\log D_{\text {ow }}$ decreases as a compound becomes ionized. The indicated $\mathrm{pH}$ values correspond to $\mathrm{pK}_{a}+2$ for weak bases and to $\mathrm{pK}_{a}-2$ for weak acids. At these $\mathrm{pH}$ values, $\sim 1 \%$ of the solute is charged and the ionized form begins to be important

and 5-Fu in a WWTP effluent matrix; and (4) determine CytR and 5-Fu adsorption kinetics with respect to contact time in the WWTP.

\section{Materials and methods}

\section{Adsorbents}

Two commercially available PACs were tested: Norit SAE Super (Norit, Amersfoort, the Netherlands) and Activated Lignite HOK Super (RWE Power-Rheinbraun Brennstoff, Frechen, Germany). Adsorbents were dried in an oven for $3 \mathrm{~h}$ at $150^{\circ} \mathrm{C}$ (ASTM 2003) prior to storage in glass bottles with PTFE-lined screw caps. The point of zero charge $\left(\mathrm{pH}_{\mathrm{PZC}}\right)$ was determined in this study using a mass titration method ( $\mathrm{Li}$ et al. 2002). Table 1 summarizes the properties of the studied adsorbents.

\section{Adsorbates}

The adsorbates 5-Fu and CytR were purchased from SigmaAldrich (Seelze, Germany). Individual stock solutions $\left(200 \mathrm{mgL}^{-1}\right)$ were prepared in Millipore water and stored in the dark at $4{ }^{\circ} \mathrm{C}$ for up to 3 weeks. Labeled internal standards, $\left[{ }^{15} \mathrm{~N}_{2}\right] 5$-Fu and $\left[{ }^{13} \mathrm{C}_{3}\right]$ CytR, were used for 
Table 1 Adsorbent

characteristics

${ }^{a}$ Information provided by manufacturers in 2009

(average values)

\begin{tabular}{lcccllr}
\hline & $\mathrm{pH}_{\mathrm{PZC}}$ & $\begin{array}{l}\text { Surface area } \\
\left(\mathrm{m}^{2} \mathrm{~g}^{-1}\right)^{\mathrm{a}}\end{array}$ & $\begin{array}{l}\text { Particle size } D_{50} \\
(\mu \mathrm{m})^{\mathrm{a}}\end{array}$ & $\begin{array}{l}\text { Raw } \\
\text { material }^{\mathrm{a}}\end{array}$ & $\begin{array}{l}\text { Activation } \\
\text { method }^{\mathrm{a}}\end{array}$ & ${\text { Price }(€ / t)^{\mathrm{a}}}$ \\
\hline SAE Super & 9.8 & 1,300 & 15 & Peat/wood & Steam & 1,200 \\
HOK Super & 10 & 300 & 24 & Lignite & Steam & 380 \\
\hline
\end{tabular}

analytical quality assurance. Adsorbate concentrations were measured by high-performance liquid chromatography (HPLC) and tandem mass spectrometry (MS/MS; HP1100, Agilent, Waldbronn, Germany, coupled with an API 3000 mass spectrometer, Applied Biosystems, Foster City, CA, USA). Samples from experiments with an initial adsorbate concentration of $200 \mathrm{\mu gL}^{-1}$ were diluted to $50 \%$ with acetonitrile, and a $2-\mu \mathrm{L}$ aliquot was analyzed. Compound separation was accomplished with a ZIC-HILIC column (SeQuant, Umea, Sweden). Limits of quantification (LOQs) were 0.5 and $1 \mu \mathrm{gL}^{-1}$ for 5 -Fu and CytR, respectively. Samples from experiments with an initial adsorbate concentration of $0.8 \mathrm{\mu gL}^{-1}$ were preconcentrated by solid phase extraction (SPE) on 1,000 mg Isolute $\mathrm{ENV}^{+}$(Separtis, Grenzach-Wyhlen, Germany). LOQs for preconcentrated samples were 15 and $3 \mathrm{ngL}^{-1}$ for 5 -Fu and CytR, respectively. Analytical procedures have been described in a prior publication (Kovalova et al. 2009).

For reference, the less polar adsorbates bisphenol A (BPA, Sigma-Aldrich, Steinheim, Germany) and 17- $\alpha$ ethinylestradiol (EE2, Sigma-Aldrich, Steinheim, Germany) were also studied. Details of the employed analytical method (HPLC with fluorescent detection) are described elsewhere (Lehnberg et al. 2009).

\section{Water matrices}

Single-solute adsorption isotherm experiments were performed in 5 and $100 \mathrm{mM}$ phosphate buffers at pH6.2, 7.8, and 9.6. The $5 \mathrm{mM}$ phosphate buffer with $\mathrm{pH} 7.8$ was selected to match the conductivity and $\mathrm{pH}$ of the WWTP effluent described below.

WWTP effluent used for the experiments originated from the municipal wastewater treatment plant in Aachen Soers, Germany. Approximately 100 L of treatment plant effluent was collected, thoroughly mixed and stored in 2-L polyethylene bottles at $-20{ }^{\circ} \mathrm{C}$. Prior to experiments, bottle contents were thawed at room temperature and filtered (GF/F filter, Whatman, Dassel, Germany). The $\mathrm{pH}$ of the WWTP effluent was 7.8, the total organic carbon (TOC) concentration was $5 \mathrm{mgL}^{-1}$, and the conductivity $1.2 \mathrm{mS} \mathrm{cm}^{-1}$.

Concentrated WWTP effluent was obtained by nanofiltration using a membrane with a molecular weight cutoff of $200 \mathrm{Da}$. The concentrated effluent originated from the same WWTP as the effluent described above, but from a sample collected at a different time. The $\mathrm{pH}$ of the concentrated effluent was 7.8 , the TOC concentration was $20 \mathrm{mgL}^{-1}$, and the conductivity $3.3 \mathrm{mScm}^{-1}$.

Adsorption isotherm and kinetic experiments

Separate adsorption isotherm experiments were performed for each adsorbate in 250-mL Erlenmeyer flasks containing different amounts of PAC. Two blanks with no added carbon were included with each isotherm experiment. Subsequently, $100 \mathrm{~mL}$ of WWTP effluent or buffer spiked with 200 or $0.8 \mathrm{\mu LL}^{-1}$ of a single adsorbate was transferred into the flasks. The content of the flasks was shaken in isothermal incubators at $100 \mathrm{rpm}$ at 4 or $20{ }^{\circ} \mathrm{C}$ for $16 \mathrm{~h}$. Samples were thereafter filtered (IC Acrodisc syringe filter, $45 \mu \mathrm{m}$, Pall) and analyzed as described above. The chosen adsorbateadsorbent contact time was sufficient to reach nearequilibrium conditions, as assessed via kinetic tests and mathematical modeling of the kinetic data. Adsorption isotherm data were used to evaluate the effects of adsorbate polarity, solution $\mathrm{pH}$, ionic strength, temperature, and effluent organic matter (EfOM) on 5-Fu and CytR adsorption capacities.

Kinetic experiments were performed in 1-L Erlenmeyer flasks that contained a given amount of PAC. Subsequently, $400 \mathrm{~mL}$ of WWTP effluent spiked with $200 \mathrm{\mu gL}^{-1}$ of a single adsorbate was transferred into the flasks. Experiments were conducted in duplicate. The contents of the flasks were shaken in isothermal incubators (Multitron 2, Infors HT) at $100 \mathrm{rpm}$ and $20{ }^{\circ} \mathrm{C}$ for up to $21 \mathrm{~h}$. Samples of $1 \mathrm{~mL}$ were taken by syringe and were immediately filtered. The sum of all of the withdrawn samples decreased the total volume by no more than $2.5 \%$. An aliquot of $0.5 \mathrm{~mL}$ filtrate was transferred into HPLC vials, diluted with $0.5 \mathrm{~mL}$ acetonitrile, spiked with labeled internal standard to $100 \mathrm{\mu gL}^{-1}$, and analyzed by HPLC-MS/MS.

Kinetic experiments with an initial adsorbate concentration of $0.8 \mu \mathrm{gL}^{-1}$ were performed in ten $250-\mathrm{mL}$ Erlenmeyer flasks, eight of which contained $500 \mathrm{mgL}^{-1}$ of PAC. Subsequently, $100 \mathrm{~mL}$ of WWTP effluent spiked with $0.8 \mu \mathrm{gL}^{-1}$ of each adsorbate was transferred into the flasks. The contents of the flasks were shaken as described above and at each sampling time point the entire content of one flask was immediately filtered $(50 \mathrm{~mm}$ cellulose acetate filter, $0.45 \mu \mathrm{m}$, Sartorius) and preconcentrated by SPE. 
The extracts were spiked with labeled internal standard and analyzed by HPLC/MS-MS.

\section{Results and discussion}

\section{Adsorbent properties}

For ionic adsorbates, adsorbent surface charge also plays a role in adsorption (Newcombe and Dixon 2006). The surface of activated carbon is always charged due to the presence of acidic and basic functional groups on pore surfaces. The $\mathrm{pH}_{\mathrm{PZC}}$ identifies the $\mathrm{pH}$ at which the net surface charge of the carbon is zero; i.e., at this $\mathrm{pH}$ there are as many positively as negatively charged surface functional groups. When the solution $\mathrm{pH}$ is lower (higher) than the $\mathrm{pH}_{\mathrm{PZC}}$, the net charge of the carbon surface is positive (negative). Figure 2 shows the ionization state of the two adsorbates and HOK Super PAC as a function of solution $\mathrm{pH}$. Because of the similarity in $\mathrm{pH}_{\mathrm{PZC}}$ values of the two tested PACs (Table 1), the $\mathrm{pH}$ dependence of the surface charge of SAE Super would be similar to that of HOK Super. As illustrated in Fig. 2, both PACs exhibited a net positive surface charge at the solution $\mathrm{pH}$ values, at which experiments were conducted (pH6.2, 7.8, and 9.6). CytR was predominantly present in neutral form while the ionization state of 5-Fu changed from predominantly neutral at pH6.2 to predominantly anionic at $\mathrm{pH} 9.6$.

Single-solute isotherms

\section{Effect of adsorbate polarity}

To put the adsorbability of 5-Fu and CytR into context, singlesolute adsorption isotherm results for $5-\mathrm{Fu}$ and $\mathrm{CytR}$ were compared to those obtained for the less polar BPA and EE2 (Fig. 3). The adsorption behavior of the three adsorbates that

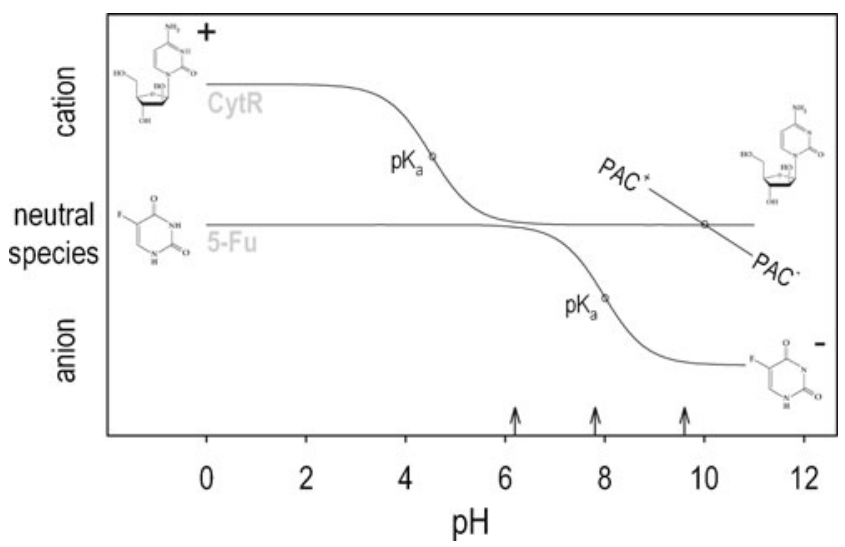

Fig. 2 Changes in ionization state of 5-fluorouracil, cytarabine and PAC (HOK Super) as a function of solution $\mathrm{pH}$. Arrows indicate the $\mathrm{pH}$ at which adsorption experiments were performed

\begin{tabular}{|c|c|c|c|c|}
\hline \multicolumn{5}{|c|}{ Freundlich parameters $\left(q=K_{F}, c^{l / n}\right)$ : } \\
\hline & \multicolumn{2}{|c|}{$K_{F} \pm$ Std. Error } & \multicolumn{2}{|c|}{$1 / n \pm$ Std. Error } \\
\hline EE2 & 5.92 & $\pm \quad 0.46$ & 0.24 & \pm 0.02 \\
\hline BPA & 5.09 & \pm 0.54 & 0.20 & \pm 0.03 \\
\hline OytR & 0.75 & $\pm \quad 0.07$ & 0.41 & $\pm \quad 0.02$ \\
\hline 5-Fu & 0.57 & $\pm \quad 0.02$ & 0.43 & \pm 0.01 \\
\hline
\end{tabular}

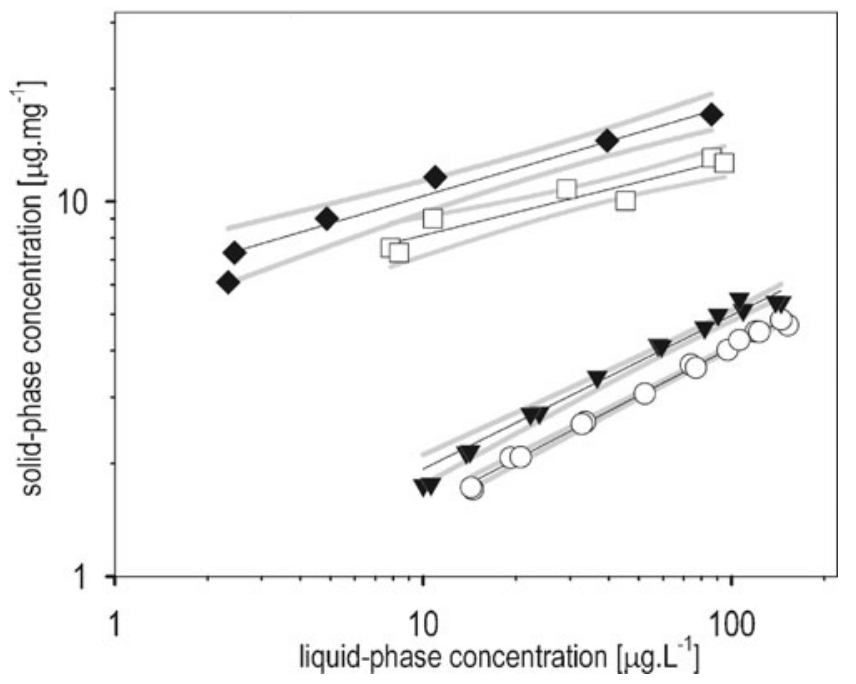

Fig. 3 Comparison of single-solute adsorption isotherms for polar (5$\mathrm{Fu}$ and $\mathrm{CytR}$ ) and less polar (EE2 and BPA) adsorbates. Adsorbent: Activated Lignite HOK Super. Units of Freundlich $K_{F}$ values are $(\mu \mathrm{g}$ $\left.\mathrm{mg}^{-1}\right)\left(\mu \mathrm{gL}^{-1}\right)^{-(1 / n)}$. Gray lines represent $95 \%$ confidence bands. Experimental conditions: $5 \mathrm{mM}$ phosphate buffer $\mathrm{pH} 7.8$ spiked with $200 \mu \mathrm{gL}^{-1}$ adsorbate, $20^{\circ} \mathrm{C}, 100 \mathrm{rpm}, 16 \mathrm{~h}$ contact time

are neutral at pH7.8 (EE2, BPA, CytR) corresponds to what is expected from octanol/water partition coefficients (Fig. 1). EE2 is the most hydrophobic, $\log K_{\mathrm{ow}}=4.2$, (Robinson et al. 2009) and adsorbs most strongly, followed by BPA, log $K_{\mathrm{ow}}=3.4$, (Robinson et al. 2009), and CytR, $\log K_{\mathrm{ow}}=-2.1$, (Romanova and Novotny 1996). $K_{\text {ow }}$ can be used to estimate the adsorbability of neutral adsorbates, for which dispersive interactions dominate. Nonspecific interactions between neutral micropollutants and the activated carbon surface are expected to dominate in aqueous systems, as surface sites suitable for specific interactions (e.g., hydrogen bonding) are expected to interact primarily with water (e.g., Li et al. 2002). Negatively charged 5-Fu exhibited the lowest adsorption capacity of the four tested micropollutants even though attractive Coulombic interactions between the positively charged PAC surface and anionic 5-Fu may have contributed to 5-Fu adsorption. The most likely reason for the low adsorbability of 5-Fu at $\mathrm{pH} 7.8$ is its high aqueous solubility, which is predicted to be $604 \mathrm{gL}^{-1}$ at $\mathrm{pH}$ 8 (SciFinder Scholar 2011).

The Freundlich adsorption constants $\left(K_{F}\right)$ listed in Fig. 3 reveal that the adsorption capacity of HOK Super for the polar adsorbates was approximately 1 order of magnitude lower than for the less polar ones. The Freundlich exponent is higher for the polar adsorbates. The steeper slope for polar adsorbates indicates a stronger dependence of adsorption uptake on PAC concentration. 
To remove $90 \%$ of the adsorbate from $5 \mathrm{mM}$ phosphate buffer in a single-solute solution, $14,18,70$, and $87 \mathrm{mgL}^{-1}$ of HOK Super is required for EE2, BPA, CytR, and 5-Fu, respectively. At doses of carbon to remove this percentage of the less polar micropollutants, over $50 \%$ of the polar micropollutants remain solved. This was observed for single-solute experiments as well as for experiments in the presence of EfOM from WWTP effluent (Electronic supplementary material (ESM) Fig. S1).

\section{Influence of solution $\mathrm{pH}$}

Solution $\mathrm{pH}$ is an important factor controlling the adsorption of ionizable compounds (Newcombe and Dixon 2006). Single-solute adsorption isotherm data were collected for $5-\mathrm{Fu}$ and CytR on HOK Super at three $\mathrm{pH}$ values. As illustrated in Fig. 4a, 5-Fu adsorption was lower at pH9.6 than at $\mathrm{pH} 7.8$ and 6.2. Raising the $\mathrm{pH}$ in the vicinity of 5-Fu $\mathrm{pK}_{a}$ of 8.0 increases the fraction of negatively charged species (Fig. 2). At the same time, increasing the $\mathrm{pH}$ decreases the concentration of positively charged functional groups on activated carbon pore surfaces and thus the possibility of electrostatic attraction. Nonetheless, the net surface charge of HOK Super stays on average positive until the solution $\mathrm{pH}$ reaches the $\mathrm{pH}_{\mathrm{PZC}}$ of 10.0 . Therefore, the lower 5-Fu adsorption capacity at $\mathrm{pH} 9.6$ is attributed to the higher aqueous solubility of 5-Fu at $\mathrm{pH} 9.6$, at which the more soluble anionic form dominates. Varying the solution $\mathrm{pH}$ from 6.2 to 9.6 had no measurable influence on the adsorption characteristics of CytR as the adsorbate was predominantly in its neutral form over the tested $\mathrm{pH}$ range.

The addition of different carbon doses into the unbuffered solution results in a gradual change in the $\mathrm{pH}$ of the system. When a 5-Fu adsorption isotherm experiment was conducted with HOK Super in unbuffered ultrapure water (data not shown), a curve overlapping the pH6.2 data in Fig. 4a was obtained at the $\mathrm{pH}$ range of 5.6-6.5 (low carbon doses) and a curve overlapping the $\mathrm{pH} 9.6$ data at the $\mathrm{pH}$ range of 9.1-10.0 (high carbon doses). The part of the curve in between the two ranges had a steep slope and represented carbon doses of $60-100 \mathrm{mgL}^{-1}$. This result implies that isotherm data collected in unbuffered systems without any $\mathrm{pH}$ control can be misleading because the change in solution $\mathrm{pH}$ associated with the addition of high PAC doses can influence both the ionization state of the adsorbate and the net surface charge of the carbon. On the other hand, buffered systems are not truly single-solute systems and a competition between buffer components and a micropollutant can occur.

\section{Influence of ionic strength}

To determine the effect of solution ionic strength on 5-Fu and CytR adsorption, adsorption isotherm experiments were
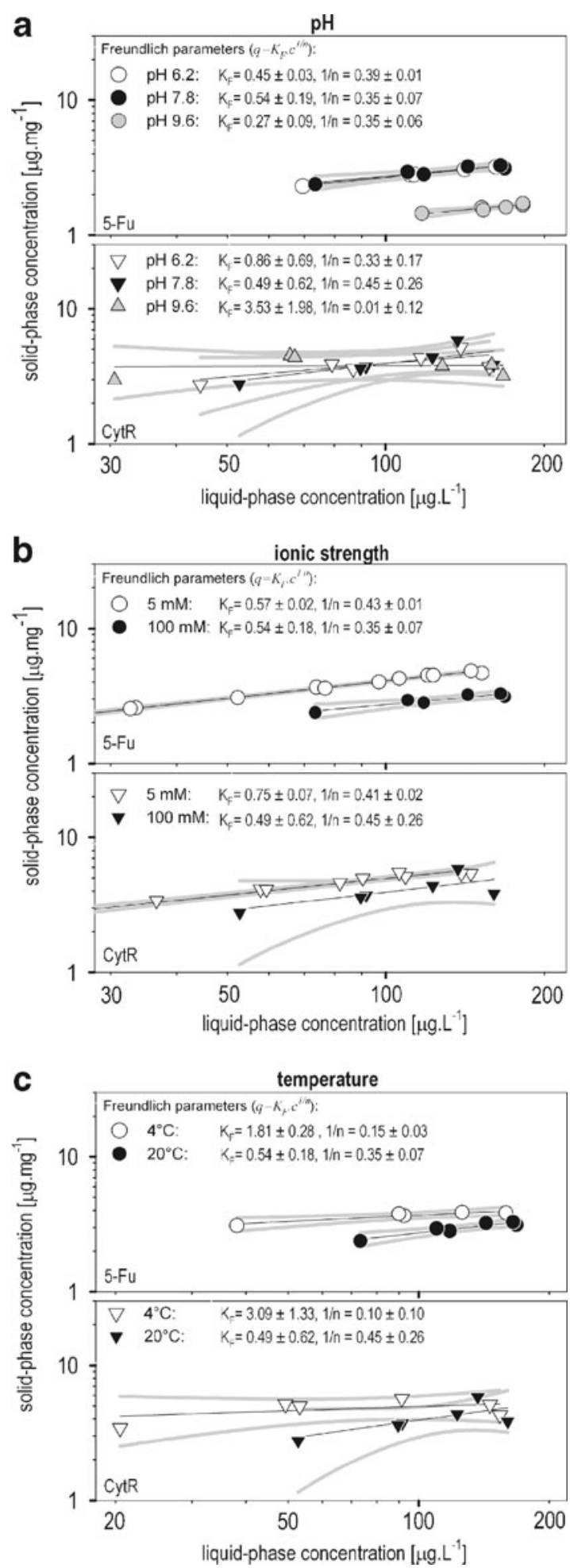

Fig. 4 Effects of $\mathrm{pH}$ (a), ionic strength (b), and temperature (c) on single-solute adsorption isotherms of 5-fluorouracil and cytarabine on Activated Lignite HOK Super. Freundlich isotherm parameters and standard errors are indicated for each experimental condition $\left(K_{F}\right.$ units are $\left.\left(\mu \mathrm{g} \mathrm{mg}^{-1}\right)\left(\mu \mathrm{gL}^{-1}\right)^{-(1 / \mathrm{n})}\right)$. Gray lines represent $95 \%$ confidence bands. Experimental conditions: a-c initial adsorbate concentration $200 \mu \mathrm{gL}^{-1}$; $100 \mathrm{rpm}$; contact time $16 \mathrm{~h}$. a $100 \mathrm{mM}$ phosphate buffers; pH6.2, 7.8, or $9.6 ; 20{ }^{\circ} \mathrm{C}$. b 5 or $100 \mathrm{mM}$ phosphate buffers; $\mathrm{pH} 7.8$; $20{ }^{\circ} \mathrm{C}$. c $100 \mathrm{mM}$ phosphate buffer; $\mathrm{pH} 7.8 ; 4^{\circ}$ or $20^{\circ} \mathrm{C}$ 
conducted in 5 and $100 \mathrm{mM}$ phosphate buffers at $\mathrm{pH} 7.8$ (Fig. 4b). For 5-Fu, the increase in ionic strength decreased adsorbability as evidenced by a statistically significant increase in the Freundlich adsorption constant $K_{F}(p=0.05)$. At the tested $\mathrm{pH}$ of 7.8 , the net surface charge of HOK Super is positive, while 5 -Fu is partially ionized (less than $50 \%$ anionic). It is believed that competition with buffer components or screening of the attractive electrostatic interactions between HOK Super and 5-Fu was more pronounced at the higher ionic strength, resulting in a lower adsorption capacity.

At $\mathrm{pH} 7.8$, CytR is predominantly present in its neutral form. Although the results in Fig. 4b suggest that an increase in ionic strength lowered the adsorptive uptake of CytR, the difference is not statistically significant at $95 \%$ confidence level. For neutral hydrophobic compounds, it was previously demonstrated that an increase in ionic strength can lead to a considerable increase in adsorption capacity (Toledo et al. 2005). This result was associated with the salting-out effect (decreasing aqueous solubility with increasing ionic strength, which leads to enhanced adsorbate uptake by PAC). However, this trend was not observed with the more hydrophilic adsorbate CytR at the ionic strengths evaluated here.

\section{Influence of temperature}

As shown in Fig. 4c, the major effect of temperature was a change in isotherm slope (Freundlich exponent $1 / n$ ). As temperature increased, $1 / n$ increased. Similar trends were observed for both 5 -Fu and CytR, although confidence bands for the CytR isotherms partially overlap. For atrazine, steeper single-solute isotherm slopes with increasing temperatures were previously reported (Schreiber et al. 2007). As a result of the change in $1 / n$ value, a lower temperature resulted in higher adsorptive uptake of 5-Fu and CytR over a wide range of adsorbate concentrations. The effect of temperature on adsorption can be explained by the exothermic nature of adsorption processes (Moreno-Castilla 2004).

\section{Isotherms in multisolute systems}

The presence of EfOM in WWTP effluent greatly lowered the adsorption uptake of both 5-Fu and CytR. Figure 5 compares adsorption isotherms performed in $5 \mathrm{mM}$ phosphate buffer and WWTP effluent, which had the same $\mathrm{pH}$ and conductivity. The extent to which adsorption is hindered by EfOM is considerably stronger than any adverse influences resulting from $\mathrm{pH}$, ionic strength, or temperature. During PAC adsorption, micropollutant uptake is adversely affected by direct competition from background organic matter (here EfOM) constituents for adsorption sites. The adsorption competition is less pronounced at high than at low carbon doses, where the availability of adsorption sites is more limited. The change in

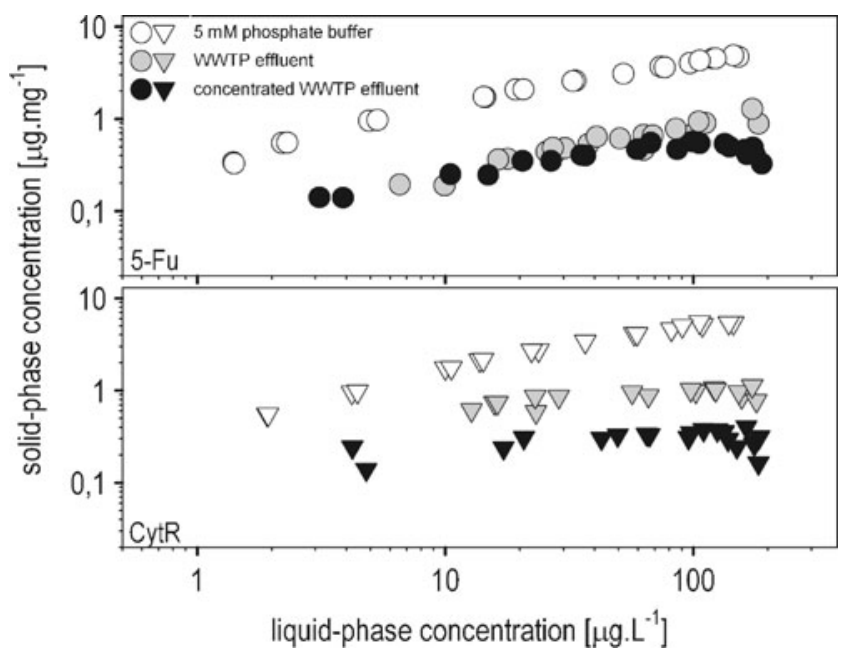

Fig. 5 Effects of matrix compounds on adsorption isotherms of 5fluorouracil and cytarabine on Activated Lignite HOK Super. Experimental conditions: spiked $200 \mu \mathrm{gL}^{-1}$ of a single adsorbate in $5 \mathrm{mM}$ phosphate buffer, WWTP effluent, or concentrated WWTP effluent; pH $7.8 ; 20^{\circ} \mathrm{C} ; 100 \mathrm{rpm}$; contact time $16 \mathrm{~h}$

the extent of the competitive influence is reflected in the curvature of the isotherms in the WWTP effluent matrix. In the presence of EfOM exhibit, isotherms on a log-log scale an adsorption maximum and a drop in the solid-phase concentration to the right of that maximum (i.e., as the carbon dose is decreased). This loss in adsorption capacity is most clearly illustrated with the results obtained in concentrated WWTP effluent (Fig. 5) and can be explained by the adsorption of strongly competing compounds on the ever more limited number of adsorption sites as the PAC dose is decreased. Low-molecular weight EfOM compounds, resp. EfOM compounds with molecular sizes comparable to those of the target micropollutants, are the major contributors to the reduction in the adsorption capacity (Yu et al. 2012).

While the single-solute isotherm data of 5-Fu and CytR could be well described by the Freundlich isotherm model (Figs. 3 and 4), 5-Fu and CytR isotherm data $\left(\mathrm{C}_{0}=200 \mu \mathrm{g}\right.$ $\mathrm{L}^{-1}$ ) obtained with HOK Super and SAE Super in the WWTP effluents matrix were effectively described by a pseudo-single solute isotherm (Qi et al. 2007), as shown in Fig. 6 and ESM Fig. S2. This was also demonstrated by the good model prediction of 5-Fu and CytR adsorption at an initial concentration of $0.8 \mu \mathrm{gL}^{-1}$ (Fig. 6a). Details about the procedure used to obtain pseudo-single solute isotherm fits and predictions are provided in the ESM. Plotting isotherm data in a format showing the remaining aqueous adsorbate percentage as a function of PAC dose (Knappe et al. 1998), the data in Fig. 6b illustrate that SAE Super provided higher adsorption capacities for both target adsorbates when compared to HOK Super. This result is largely explained by the different surface areas of the two adsorbents. The PAC doses required to achieve $90 \%$ removal of 


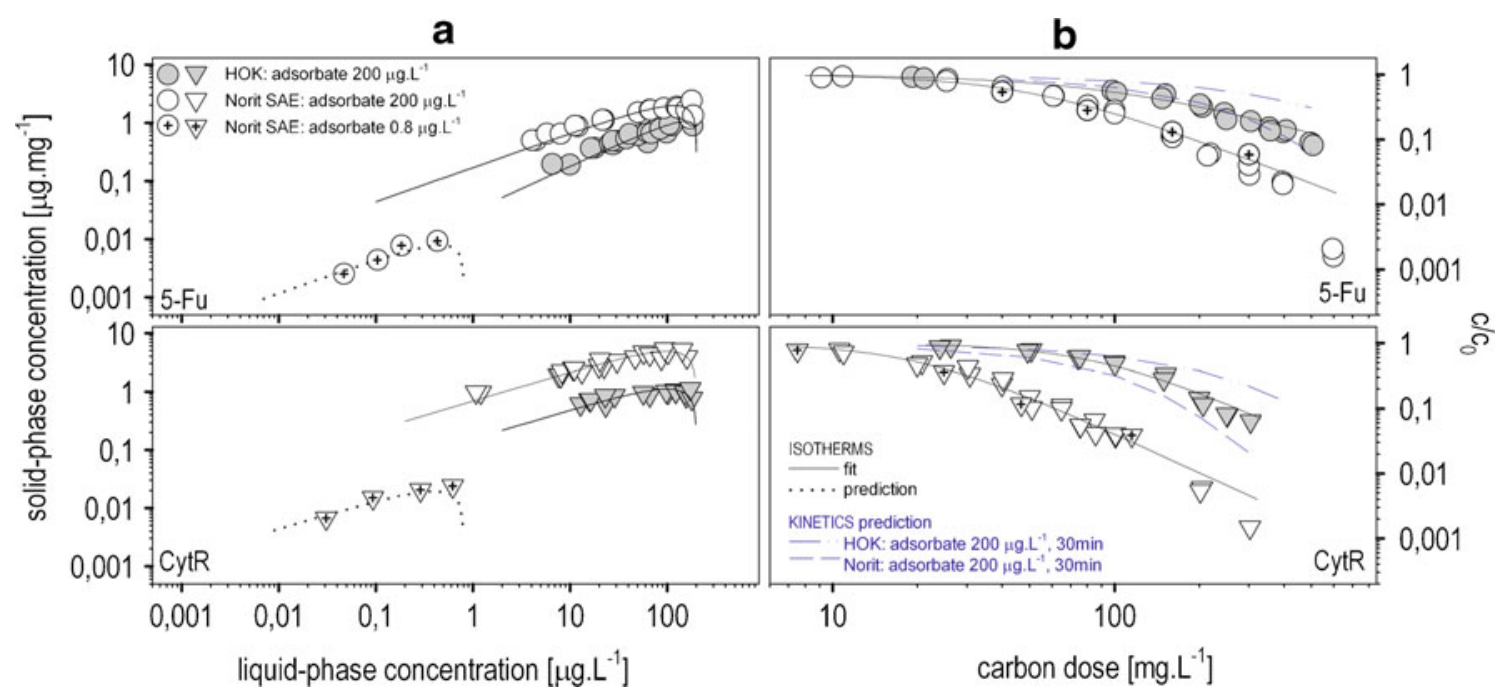

Fig. 6 Pseudo-single solute isotherm fits, predictions, and kinetics predictions for WWTP effluent. Experimental conditions: WWTP effluent spiked with $200 \mu \mathrm{gL}^{-1}$ (open or light solid symbols) or $0.8 \mu \mathrm{g}$

$\mathrm{L}^{-1}$ (symbols with positive sign inside) of a single adsorbate, $\mathrm{pH} 7.8$, $20{ }^{\circ} \mathrm{C}, 100 \mathrm{rpm}, 16 \mathrm{~h}$ contact time

the target adsorbates are approximately three times higher for HOK Super than for SAE Super (Fig. 6b and ESM Fig. S1), which has 4.3 times larger surface area than HOK Super (Table 1) and possibly different functional groups on its surface. The results obtained at initial target compound concentrations of 200 and $0.8 \mu \mathrm{gL}^{-1}$ further show that the percentage of target compound removal at a given PAC dose is independent of the initial target compound concentration (Fig. 6b). The results obtained here with WWTP effluent are in agreement with those obtained with both polar and apolar compounds in surface water matrices (Knappe et al. 1998; Rossner et al. 2009).

\section{Adsorption kinetics}

Adsorption kinetic tests were conducted with both 5-Fu and CytR in WWTP effluent. Initial target compound concentrations were 200 and $0.8 \mu \mathrm{gL}^{-1}$, and SAE Super and HOK Super doses for kinetic tests ranged from 20 to $500 \mathrm{mgL}^{-1}$. Results from a representative kinetic test describing CytR adsorption by HOK Super are shown in Fig. 7. The data were mathematically described by the homogeneous surface diffusion model (HSDM) using a pseudo-single solute approach (Qi et al. 1994). The results in Fig. 7 illustrate that a single surface diffusion coefficient $\left(D_{s}\right)$ effectively described adsorption kinetic data at the two tested PAC doses and the two tested initial adsorbate concentrations. Those data confirm results from prior studies showing that percent target compound removal as a function of time is independent of the initial target compound concentration (Gillogly et al. 1998; Zoschke et al. 2011). $D_{s}$ values describing 5-Fu and CytR adsorption were similar on a given adsorbent but were about 1 order of magnitude smaller on SAE Super than on HOK Super (1.4

$3.5 \times 10^{-11} \mathrm{~cm}^{2} \mathrm{~s}^{-1}$ on HOK Super, $2.9-4.3 \times 10^{-12} \mathrm{~cm}^{2} \mathrm{~s}^{-1}$ on SAE Super). Differences in $D_{s}$ values were likely a result of differences in pore structures between the two PACs with HOK Super containing a higher percentage of the total pore volume in the meso- and macropore range (Wirling 2001).

The HSDM was used to predict the effect of a limited contact time $(30 \mathrm{~min})$ on the PAC dose required to achieve a desired 5-Fu and CytR removal percentage. A PAC contact time of $30 \mathrm{~min}$ is fairly typical if PAC were added to a tertiary physical-chemical treatment train that follows biological treatment in a WWTP. Compared to

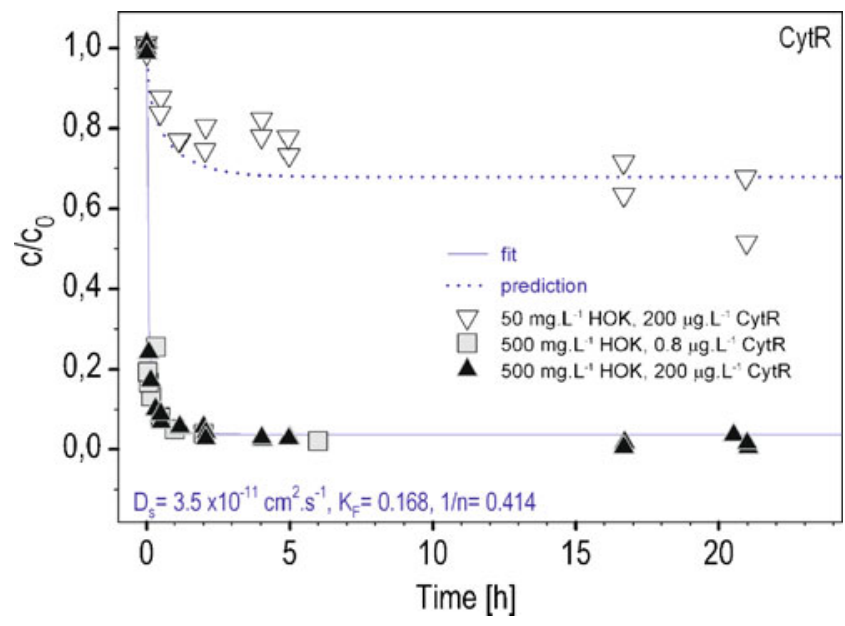

Fig. 7 Adsorption kinetic data describing CytR adsorption from WWTP effluent by HOK Super. Lines represent HSDM fit (500 mg $\mathrm{L}^{-1}$ HOK Super dose) and prediction $\left(50 \mathrm{mgL}^{-1} \mathrm{HOK}\right.$ Super dose). The surface diffusion coefficient was estimated with the data set obtained at an initial CytR concentration of $200 \mu \mathrm{gL}^{-1}$ and an HOK Super dose of $500 \mathrm{mgL}^{-1}$. Experimental conditions: WWTP effluent spiked with 200 or $0.8 \mu \mathrm{gL}^{-1}$ of CytR, $\mathrm{pH} 7.8,20^{\circ} \mathrm{C}, 100 \mathrm{rpm}$ 
the isotherm data, which is representative of the removal percentages that may be achieved if PAC is added to the aeration basin of a WWTP and incubated for several hours, substantially larger PAC doses are required to achieve a given 5-Fu and CytR removal percentage in 30 min (Fig. 6b). For example, to achieve $70 \% 5$-Fu and CytR removal in $30 \mathrm{~min}$ would require HOK Super doses of about 500 and $250 \mathrm{mgL}^{-1}$, respectively, and SAE Super doses of about 250 and $100 \mathrm{mgL}^{-1}$, respectively. At a pseudo-equilibrium contact time of $16 \mathrm{~h}$, $70 \% 5-\mathrm{Fu}$ and CytR removal would be achieved with HOK Super doses of about 200 and $140 \mathrm{mgL}^{-1}$, respectively, and SAE Super doses of about 90 and $30 \mathrm{mgL}^{-1}$, respectively (Fig. 6b and ESM Fig. S2).

\section{Summary and conclusions}

This study focused on the adsorption behavior of highly polar micropollutants $\left(\log K_{\mathrm{ow}}\right.$ below -1$)$ onto powdered activated carbon for their removal from wastewater. The findings can be summarized as follows:

- Adsorption capacity of HOK Super for the polar 5-Fu and CytR was approximately 1 order of magnitude lower than for the less polar BPA and EE2. Doses of carbon sufficient to remove over $90 \%$ of apolar adsorbates are able to remove approximately $50 \%$ of polar 5-Fu and CytR.

- Statistically significant influence of the solution $\mathrm{pH}$ and ionic strength on the carbon adsorption capacity was observed only for the charged 5-Fu, with higher adsorption capacities at lower $\mathrm{pH}$ values and weaker ionic strengths.

- Background organic matter decreased adsorption capacities to a greater extent than $\mathrm{pH}$, ionic strength, and temperature. This occurred especially at low carbon doses where the competition for sorption sites is strong.

- The percentage of 5-Fu and CytR removal at a given PAC dose was independent of the initial adsorbate concentration. This behavior, observed here for ionisable compounds in the presence of EfOM is analogous to that observed for non-ionizable pollutants in the presence of NOM.

- The pseudo single-solute isotherm equation proved to be a suitable tool for prediction of the adsorption behavior of polar micropollutants in a wastewater matrix.

- The percentage of adsorbate removal as a function of time was also independent of the initial adsorbate concentration.

- Comparison of the two tested PACs showed that the doses of HOK Super (with bigger particle size and smaller surface area) have to be approximately three times higher than those of SAE Super to achieve the same 5-Fu and CytR elimination efficiency. Surface diffusion coefficients for HOK Super are 1 order of magnitude higher than for SAE Super.

Acknowledgments This research project has been supported by a Marie Curie Early stage Research Fellowship of the European Community's Sixth Framework Programme under contract number MESTCT-2004-505169, as well as by the German Federal Ministry of Economics and Technology through the AiF - German Federation of Industrial Research Associations "Otto von Guericke". The authors would like to thank Bettina Sterkele from Eawag, Switzerland for fruitful and inspiring discussions, Damian Helbling, also from Eawag, for revising the manuscript, Robert McLaughlan from University of technology Sidney for checking the quality of the English, as well as Wolfgang Dott, and Thomas Schettgens from University Hospital Aachen, Germany for providing the instrumentation and lab space.

\section{References}

ASTM (2003) ASTM Standard Practice for Determination of Adsorptive Capacity of Activated Carbon by Aqueous Phase Isotherm Technique, D 3860-98, Reapproved 2003

Gillogly TET, Snoeyink VL, Elarde JR, Wilson CM, Royal EP (1998) 14C-MIB adsorption on PAC in natural water: a new way of measuring very low concentrations of MIB allows calculation of the PAC dose needed to mitigate odors caused by MIB. J Am Water Works Assoc 90(1):98-100

Johnson AC, Jurgens MD, Williams RJ, Kummerer K, Kortenkamp A, Sumpter JP (2008) Do cytotoxic chemotherapy drugs discharged into rivers pose a risk to the environment and human health? An overview and UK case study. J Hydrol 348(1-2):167-175

Jones OAH, Green PG, Voulvoulis N, Lester JN (2007) Questioning the excessive use of advanced treatment to remove organic micropollutants from wastewater. Environ Sci Technol 41(14):50855089

Joss A, Siegrist H, Ternes TA (2008) Are we about to upgrade wastewater treatment for removing organic micropollutants? Water Sci Technol 57(2):251-255

Kiffmeyer T, Gotze HJ, Jursch M, Luders U (1998) Trace enrichment, chromatographic separation and biodegradation of cytostatic compounds in surface water. Fresenius J Anal Chem 361(2):185-191

Knappe DRU, Matsui Y, Snoeyink VL, Roche P, Prados MJ, Bourbigot MM (1998) Predicting the capacity of powdered activated carbon for trace organic compounds in natural waters. Environ Sci Technol 32(11):1694-1698

Kosjek T, Heath E (2011) Occurrence, fate and determination of cytostatic pharmaceuticals in the environment. TrAC Trends Anal Chem 30(7):1065-1087. doi:10.1016/j.trac.2011.04.007

Kovalova L, McArdell CS, Hollender J (2009) Challenge of high polarity and low concentrations in analysis of cytostatics and metabolites in wastewater by hydrophilic interaction chromatography/tandem mass spectrometry. J Chromatogr A 1216(7):11001108

Kovalova L, Siegrist H, Singer H, Wittmer A, McArdell CS (2012) Hospital wastewater treatment by membrane bioreactor: performance and efficiency for organic micropollutant elimination. Environ Sci Technol 46(3):1536-1545

Lehnberg K, Kovalova L, Kazner C, Wintgens T, Schettgen T, Melin T, Hollender J, Dott W (2009) In: Kim YJ, Platt U, Gu MB, 
Iwahashi $\mathrm{H}$ (eds) Atmospheric and biological environmental monitoring: removal of selected organic micropollutants from WWTP effluent with powdered activated carbon and retention by nanofiltration. Springer, Heidelberg

Li L, Quinlivan PA, Knappe DRU (2002) Effects of activated carbon surface chemistry and pore structure on the adsorption of organic contaminants from aqueous solution. Carbon 40(12):20852100

Lipp P, Gross H-J, Tiehm A (2012) Improved elimination of organic micropollutants by a process combination of membrane bioreactor (MBR) and powdered activated carbon (PAC). Desalination Water Treat 42(1-3):65-72

Mahnik SN, Rizovski B, Fuerhacker M, Mader RM (2004) Determination of 5-fluorouracil in hospital effluents. Anal Bioanal Chem 380(1):31-35

Moreno-Castilla C (2004) Adsorption of organic molecules from aqueous solutions on carbon materials. Carbon 42(1):83-94

Newcombe G, Dixon D (2006) Interface science in drinking water treatment. Theory and Applications. Chapter 9: Surface chemistry effects in activated carbon adsorption of industrial pollutants (D.R.U. Knappe). Elsevier, London

Qi S, Adham SS, Snoeyink VL, Lykins Jr BW (1994) Prediction and verification of atrazine adsorption by powdered activated carbon. J Envir Eng Div, Am Soc Civ Engrs 120(1):202-218

Qi S, Schideman L, Marinas BJ, Snoeyink VL, Campos C (2007) Simplification of the IAST for activated carbon adsorption of trace organic compounds from natural water. Water Res 41(2):440-448

Rey RP, Padron AS, Leon LG, Pozo MM, Baluja C (1999) Ozonation of cytostatics in water medium. Nitrogen bases. Ozone Sci Eng 21 (1):69-77

Robinson BJ, Hui JPM, Soo EC, Hellou J (2009) Estrogenic compounds in seawater and sediment from Halifax Harbour, Nova Scotia, Canada. Environ Toxicol Chem 28(1):18-25

Romanova D, Novotny L (1996) Chromatographic properties of cytosine, cytidine and their synthetic analogues. J Chromatogr BBiomed Appl 675(1):9-15

Rossner A, Snyder SA, Knappe DRU (2009) Removal of emerging contaminants of concern by alternative adsorbents. Water Res 43 (15):3787-3796. doi:10.1016/j.watres.2009.06.009
SciFinder Scholar (2011) CAS. American Chemical Society. https:// scifinder.cas.org/. Accessed September 2011

Schreiber B, Schmalz V, Brinkmann T, Worch E (2007) The effect of water temperature on the adsorption equilibrium of dissolved organic matter and atrazine on granular activated carbon. Environ Sci Technol 41(18):6448-6453

Serrano D, Suarez S, Lema JM, Omil F (2011) Removal of persistent pharmaceutical micropollutants from sewage by addition of PAC in a sequential membrane bioreactor. Water Res 45(16):53235333

Toledo IB, Ferro-Garcia MA, Rivera-Utrilla J, Moreno-Castilla C, Fernandez FJV (2005) Bisphenol A removal from water by activated carbon. Effects of carbon characteristics and solution chemistry. Environ Sci Technol 39(16):6246-6250

Weissbrodt D, Kovalova L, Ort C, Pazhepurackel V, Moser R, Hollender J, Siegrist H, McArdell CS (2009) Mass flows of Xray contrast media and cytostatics in hospital wastewater. Environ Sci Technol 43(13):4810-4817

Wirling J (2001) Implementation of Process-Integrated Waste Gas Cleaning Using Activated Lignite. In: A\&WMA Specialty Conference on Hazardous Waste Combustors, A\&WMA Specialty Conference on Hazardous Waste Combustors, March 28-30, 2001, Kansas City, KS, USA, March 28-30, 2001

Yu Q, Zhang R, Deng S, Huang J, Yu G (2009) Sorption of perfluorooctane sulfonate and perfluorooctanoate on activated carbons and resin: kinetic and isotherm study. Water Res 43(4):1150 1158

Yu J, Lv L, Lan P, Zhang S, Pan B, Zhang W (2012) Effect of effluent organic matter on the adsorption of perfluorinated compounds onto activated carbon. J Hazard Mater 225-226:99-106

Zoschke K, Engel C, Bornick H, Worch E (2011) Adsorption of geosmin and 2-methylisoborneol onto powdered activated carbon at non-equilibrium conditions: Influence of NOM and process modelling. Water Res 45(15):4544-4550. doi:10.1016/ j.watres.2011.06.006

Zounkova R, Kovalova L, Blaha L, Dott W (2010) Ecotoxicity and genotoxicity assessment of cytotoxic antineoplastic drugs and their metabolites. Chemosphere 81(2):253-260. doi:10.1016/ j.chemosphere.2010.06.029 